УДК $621.181 .27-637: 662.614 .2$

В. С. КОРНИЕНКО ${ }^{1}$, А. Н. РАДЧЕНКО ${ }^{2}$, А. А. АНДРЕЕВ ${ }^{1}$, Ю. Г. ЩЕРБАК ${ }^{3}$

${ }^{1}$ Херсонский филиал Национального университета кораблестроения им. адм. Макарова, Украина

${ }^{2}$ Национальный университет кораблестроения им. адм. Макарова, Николаев, Украина

3 Черноморский национальный университет им. П. Могилы, Николаев, Украина

\title{
ВЛИЯНИЕ ЗАГРЯЗНЕНИЯ НА ТЕПЛОВУЮ ЭФФЕКТИВНОСТЬ ПОВЕРХНОСТЕЙ НАГРЕВА УТИЛИЗАЦИОННЫХ КОТЛОВ ПРИ ИСПОЛЬЗОВАНИИ ВОДОТОПЛИВНЫХ ЭМУЛЬСИЙ НА ОСНОВЕ МАЛОВЯЗКИХ ТОПЛИВ
}

\begin{abstract}
При сжигании водотопливных эмульсий с водосодержанием 30 \% в связи с уменьшением скорости низкотемпературной коррозии до допустимого уровня 0,25 мм/год в утилизационном котле возможна установка конденсационных поверхностей нагрева. Приняты значения насыпной плотности загрязнений при сжигании маловязких топлив и водотопливных эмульсий на их основе. Получень зависимости толщины слоя загрязнений от температуры стенки на основании имеющихся экспериментальных данных по интенсивности загрязнения при разных значениях температуры стенки, литературных данных и расчетных значениях насыпной плотности слоя загрязнений. Переменный характер зависимостей указывает на необходимость определения значений толщинны загрязнений для каждого соответствующего диапазона значений температуры стенки. На основании полученных зависимостей средней толщины загрязнений от температуры стенки, а также значений коэффициента эквивалентной теплопроводности, построены зависимости коэффичиентов загрязнения от температуры стенки. Полученные зависимости показывают, что при одинаковых температурах стенки при сжигании водотопливных эмульсий с водосодержанием 30\% значение коэффициентов загрязнения существенно ниже, чем при сжигании необводненного топлива. Сравнение значений коэффициента загрязнения подтверждает достоверность проведенных на экспериментальной установке исследований прочессов загрязнения и аналитически определенных величин. Были проведены расчетные исследования и построены зависимости коэффициентов теплопередачи загрязненной поверхности при температурах поверхности нагрева в диапазоне 70-210 ${ }^{\circ} \mathrm{C}$ при сжигании маловязких топлив и водотопливных эмульсий на их основе. Целесообразно оценивать влияние загрязнений по значениям тепловой эффективности, потому что они позволяют выявить общее влияние на величину коэффициента загрязнения труб и неравномерности их омывания. Полученные зависимости коэффициентов загрязнения, теплопередачи и тепловой эффективности рекомендуются при проектировании конвективных поверхностей нагрева утилизачионных котлов.
\end{abstract}

Ключевые слова: утилизаџионный котел, поверхность нагрева, загрязнения, водотопливная эмульсия, маловязкое топливо.

\section{Введение}

При сжигании водотопливных эмульсий (ВТЭ) с $\mathrm{W}^{\mathrm{r}}=30 \%$ в связи с уменьшением скорости низкотемпературной сернокислотной коррозии (НТК) до допустимого уровня $\sim 0,25$ мм/год при температурах $\mathrm{t}_{\text {ст }}$ ниже температуры точки росы паров $\mathrm{H}_{2} \mathrm{SO}_{4}$ в утилизационном котле (УК) возможна установка конденсационных поверхностей нагрева. Однако отсутствуют данные о значениях коэффициентов загрязнения как для конденсационных, так и для сухих поверхностей нагрева при сжигании ВТЭ.

В источниках [1] представлены рекомендации по проектированию конвективных поверхностей нагрева. В [1] влияние загрязнения этих поверхностей принимается $\varepsilon_{\text {загр }}=0,005 \mathrm{~m}^{2} \cdot \mathrm{K} / \mathrm{BT}$, а в [2] значе-

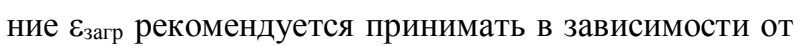
скорости газов и назначения поверхности нагрева.

\section{Постановка задачи}

Цель работы - найти зависимости коэффициентов загрязнения $\varepsilon_{\text {загр }}$, теплопередачи $\mathrm{k}_{\text {загр }}$, тепловой эффективности $\zeta$ от температуры поверхности нагрева $\mathrm{t}_{\text {ст }}$ в диапазоне $70 \ldots 210{ }^{\circ} \mathrm{C}$ при сжигании маловязких топлив с $\mathrm{W}^{\mathrm{r}}=2 \%$ и ВТЭ на их основе с

(C) В. С. Корниенко, А. Н. Радченко, А. А. Андреев, Ю. Г. Щербак 
$\mathrm{W}^{\mathrm{r}}=17 \%, \mathrm{~W}^{\mathrm{r}}=30 \%$, необходимых при проектировании поверхностей нагрева УК.

\section{Результаты исследований}

На основании проведенных экспериментальных исследований кинетики загрязнения поверхностей нагрева и полученных по их результатам зависимостей интенсивности загрязнений от $t_{\text {ст }}$ [3] воз-

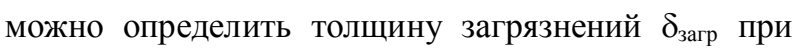
разных условиях. Для этого необходимо знать ре-

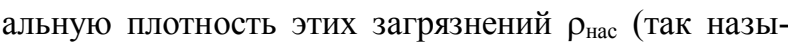
ваемую насыпную массу), зависящую от пористости слоя П, размеров, формы и упаковки твердых частиц, которые оседают из потока выхлопных газов на конденсационную поверхность нагрева.

На основании проведенных исследований и литературных данных принято, что при проведении расчетов $\rho_{\text {нас }}$ отложений при сжигании "сухого" топлива $\left(\mathrm{W}^{\mathrm{r}}=2 \%\right)$ пористость П находится на уровне 0,3 , а при сжигании эмульсии до 30 \% пористость под воздействием постоянно действующего звукового поля должна увеличиться до 0,48. Достоверность принятых допущений воздействия звукового поля на пористость оценивалась по окончательным результатам определения коэффициента загрязнения $\varepsilon_{\text {загр. }}$

На основании имеющихся экспериментальных данных по интенсивности загрязнения при разных значениях температуры стенки $\mathrm{t}_{\text {ст }}$ [3], литературных данных [4, 5] и расчетных значениях насыпной плотности слоя загрязнений по составу и при соответствующих состояниях слоев (изменение количества конденсата $\mathrm{H}_{2} \mathrm{SO}_{4}$, толщины слоя сульфатов с учетом валентности железа и концентрации кислоты в отложениях) построена зависимость $\delta_{3}$ от температуры стенки при $\tau=1000$ ч (рис. 1).

Переменный характер зависимости $\delta_{\text {загр }}$ от $\mathrm{t}_{\mathrm{cт}}$, обусловленный разным состоянием слоя загрязнений (от сухого до мокрого с промежуточным участком с парокислотной смесью), указывает на необходимость определения значений $\delta_{\text {загр }}$ для соответствующего диапазона значений $t_{\text {ст }}$ и требует соответственно проведения позонных расчетов конвективных поверхностей в зависимости от значения $\mathrm{t}_{\mathrm{cr}} \mathrm{c}$ учетом свойств выхлопных газов и слоя отложений.

Для расчетов интенсивности теплопередачи необходимо определить значения коэффициента загрязнения $\varepsilon_{3 а г р}$, определяемого отношением толщины слоя загрязнений $\delta_{\text {загр }}$ к значению эквивалентной теплопроводности слоя $\lambda_{\text {экв }}\left(\varepsilon_{\text {загр }}=\delta_{\text {загр }} / \lambda_{\text {экв }}\right)$. Учитывая сложную структуру и многокомпонентный состав загрязнений на разных поверхностях нагрева необходимо нахождение коэффициентов

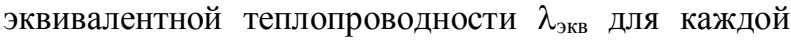
зоны температур стенки.

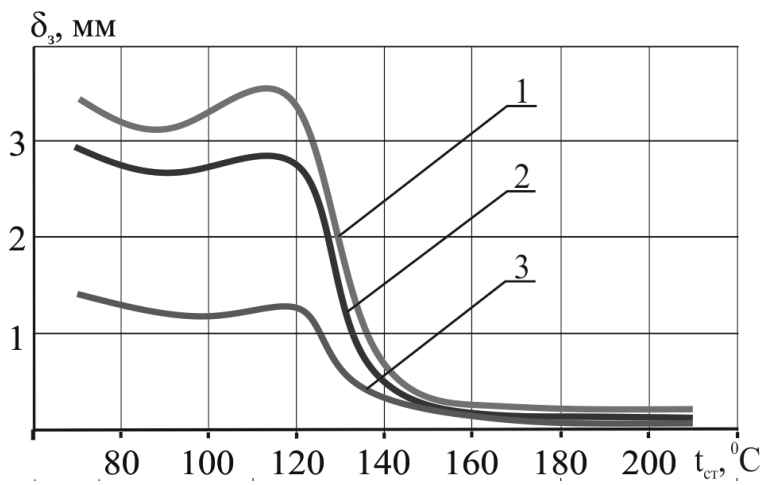

Рис. 1. Зависимость толщины слоя загрязнений $\delta_{\text {загр }}$

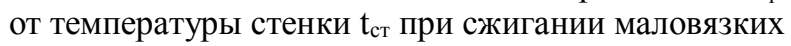
топлив и ВТЭ на его основе (по зонам поверхностей нагрева УК):

$1-\mathrm{W}^{\mathrm{r}}=2 \% ; 2-\mathrm{W}^{\mathrm{r}}=17 \% ; 3-\mathrm{W}^{\mathrm{r}}=30 \%$

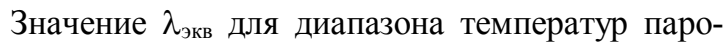
жидкостной зоны определялось по формуле [6]: $\lambda_{\text {экв }}=\lambda_{\mathrm{K}}+\left(\lambda_{\text {п.к. }}-\lambda_{\mathrm{K}}\right) \cdot x$, в которой значения коэффициентов теплопроводности конденсата серной кислоты

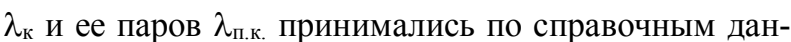
ным в зависимости от температуры и концентрации кислоты.

В результате проведенных расчетных исследований получены значения коэффициента эквивалентной теплопроводности в зависимости от $\mathrm{t}_{\text {ст }}$ для всех вариантов состояния слоя отложений при сжигании стандартного мазута с $\mathrm{W}^{\mathrm{r}}=2 \%$ и ВТЭ с $\mathrm{W}^{\mathrm{r}}=30 \%$ (рис. 2).

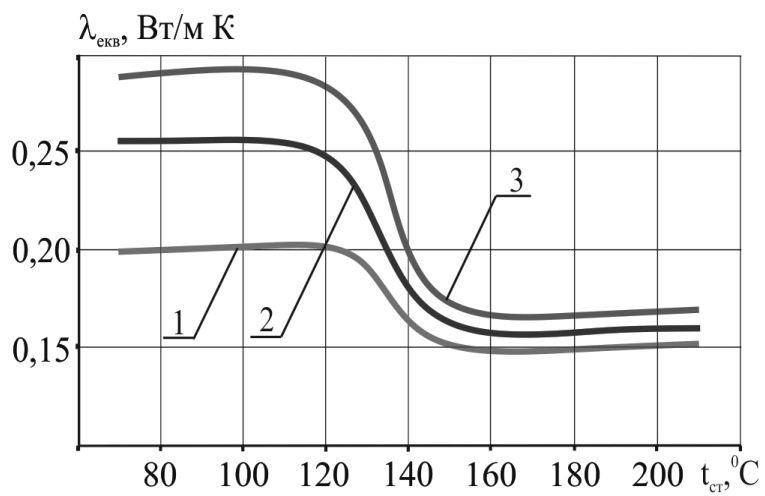

Рис. 2. Зависимость коэффициента эквивалентной теплопроводности слоя загрязнений $\lambda_{\text {экв }}$ от температуры стенки $t_{\text {ст }}$ при сжигании маловязких топлив и ВТЭ на его основе (обозначения позиций см. рис. 1)

На основании полученных зависимостей средней толщины загрязнений $\delta_{\text {загр }}$ от температуры стенки, а также значений коэффициента эквивалентной 


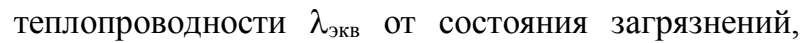
которые также зависят от величины $\mathrm{t}_{\text {ст }}$, построены зависимости коэффициентов загрязнения $\varepsilon_{\text {загр }}$ от температуры стенки $\varepsilon_{\text {загр }}=\mathrm{f}\left(\mathrm{t}_{\mathrm{cr}}\right)$ (рис. 3).

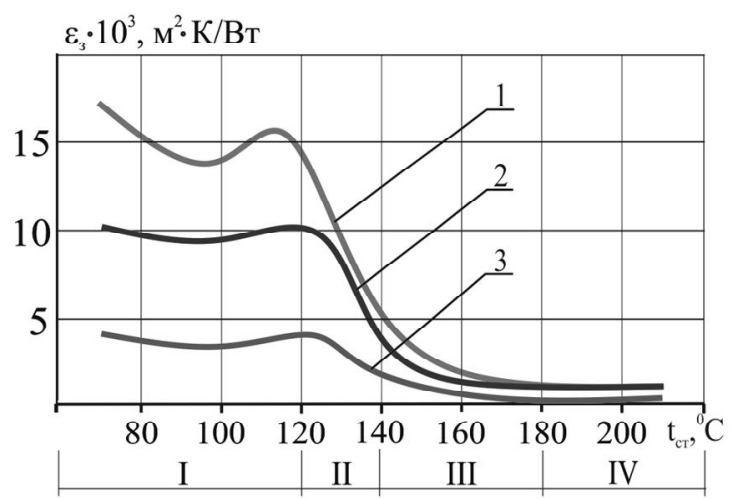

Рис. 3. Зависимость коэффициента загрязнения $\varepsilon_{\text {загр }}$ от температуры стенки $\mathrm{t}_{\text {ст }}$ при сжигании маловязких топлив и ВТЭ на его основе (по зонам поверхностей нагрева УК):

I - конденсационная поверхность; II - экономайзер; III - испаритель; IV - пароперегреватель (обозначения позиций см. рис. 1)

Основные исследования процессов загрязнения проведены на экспериментальной установке при сжигании (ДТ+ДЛ) $\left(\mathrm{S}^{\mathrm{r}}=1,5 \%, \mathrm{~W}^{\mathrm{r}}=2 \%\right)$ и ВТЭ с $\mathrm{W}^{\mathrm{r}}=30 \%$ на основе этого топлива при скорости выхлопных газов в пучках труб-образцов около 8 м/с. Поэтому предоставляется возможность сопо-

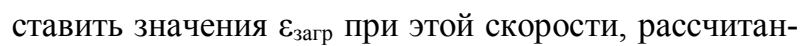
ных с учетом аналитически определенных значений $\rho_{\text {нас, }}, \delta_{\text {загр }}, \Pi, \lambda_{\text {экв}}$, полученных для режима сжигания необводненного топлива с $\mathrm{W}^{\mathrm{r}}=2 \%$, с нормативными рекомендуемыми данными для УК [2], для вспомогательного котла [1].

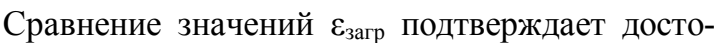
верность экспериментальных исследований процессов загрязнения и аналитически определенных ве-

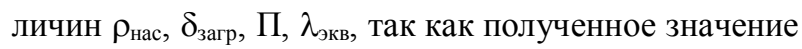

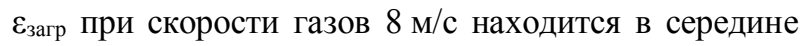

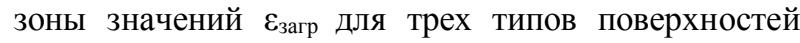
нагрева, рекомендуемых в [2].

Следовательно, следует считать достоверными и результаты аналогичных значений указанных величин при сжигании ВТЭ $\mathrm{c} \mathrm{W}^{\mathrm{r}}=30 \%$, так как исследования проведены на одной экспериментальной установке и необходимые значения $\rho_{\text {нас }}, \delta_{\text {загр }}, \Pi$,

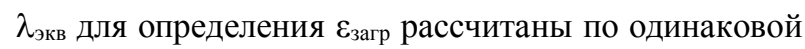
методике.

Полученные зависимости показывают, что при

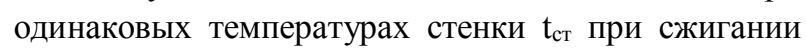
ВТЭ $\mathrm{c} \mathrm{W}^{\mathrm{r}}=30 \%$ значение коэффициентов загрязнения $\varepsilon_{\text {загр }}$ существенно ниже, чем при сжигании стан- дартного топлива с $\mathrm{W}^{\mathrm{r}}=2 \%$ : в зоне мокрых загрязнений - в 3,8 раза; в зоне сухих загрязнений - в 2,6 раза.

Найденные зависимости коэффициентов за-

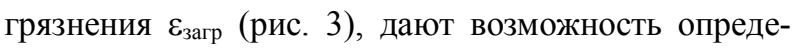
лять значения коэффициентов теплопередачи $\mathrm{k}_{\text {загр. }}$ Были проведены расчетные исследования и построены зависимости коэффициентов теплопередачи

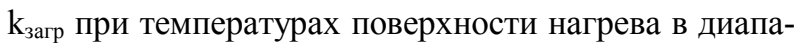
зоне $70 \ldots 210^{\circ} \mathrm{C}$ при сжигании ВТЭ и маловязких топлив (рис. 4).

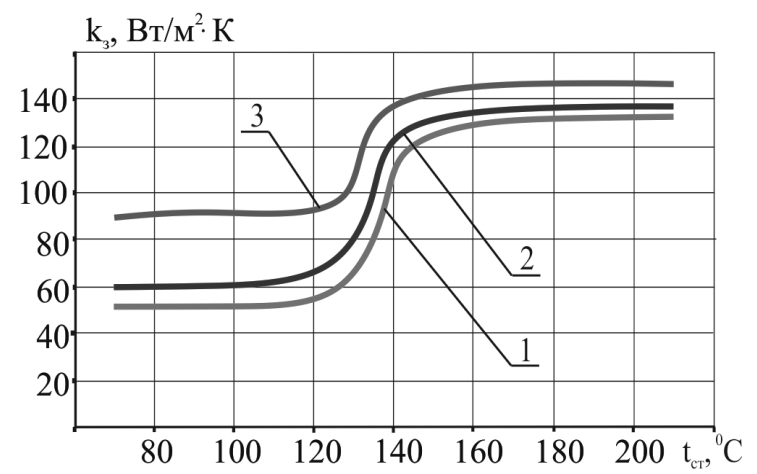

Рис. 4. Зависимость коэффициента теплопередачи

$\mathrm{k}_{\text {загр }}$ от температуры стенки $\mathrm{t}_{\mathrm{cr}}$ при сжигании маловязких топлив и ВТЭ на его основе (обозначения позиций см. рис. 1)

Согласно рекомендациям [2] при проектировании поверхностей нагрева лучше оценивать влияние загрязнений по значениям тепловой эффективности $\zeta$, так как они позволяют выявить общее влияние на величину коэффициента загрязнения труб $\mathrm{k}_{\text {загр }}$ и неравномерности их омывания.

Полученные при одинаковых условиях расчётные данные зависимости коэффициентов тепловой эффективности $\zeta$ (отношение коэффициентов теплопередачи загрязнённой и чистой поверхности) (рис. 5) показывают, что при сжигании ВТЭ с $\mathrm{W}^{\mathrm{r}}=30 \%$ значения интенсивности теплопередачи НТПН выше практически в 1,5 раза по сравнению со сжиганием стандартного топлива из $\mathrm{W}^{\mathrm{r}}=2 \%$ при $\mathrm{t}_{\text {ст }}$ ниже $130{ }^{\circ} \mathrm{C}$.

\section{Выводы}

1. Для сухих поверхностей нагрева коэффици-

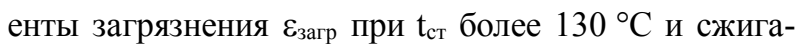
нии ВТЭ на основе мазутов с $\mathrm{W}^{\mathrm{r}}=30 \%$ при $\tau=1000$ часов в 2,4 раза ниже, чем при сжигании мазутов с $\mathrm{W}^{\mathrm{r}}=2 \%$; коэффициенты теплопередачи $\mathrm{k}_{\text {загр }}$ соответственно выше в 1,1 раза; коэффициенты тепловой эффективности $\zeta$ соответственно выше в 1,1 раза. 


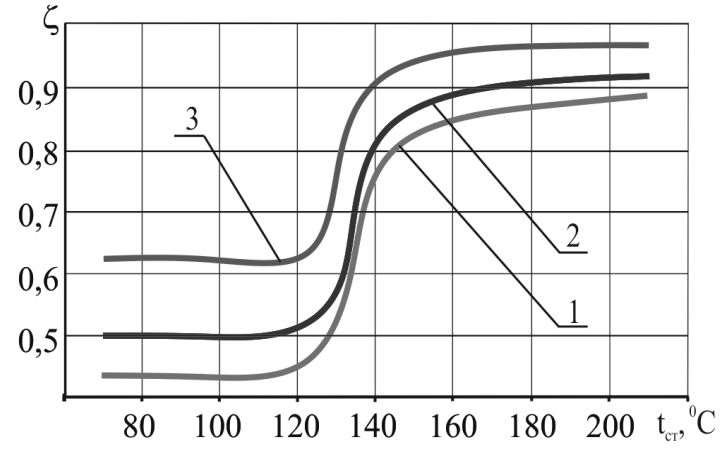

Рис. 5. Зависимость коэффициента тепловой эффективности $\zeta$ от температуры стенки $\mathrm{t}_{\text {ст }}$ при сжигании маловязких топлив и ВТЭ

на его основе (обозначения позиций см. рис. 1)

2. Для конденсационных поверхностей нагрева

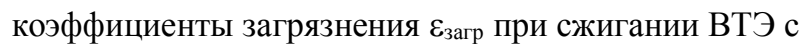
$\mathrm{W}^{\mathrm{r}}=30 \%$ в $\sim 6$ раз выше по сравнению с сухими поверхностями; коэффициенты теплопередачи $\mathrm{k}_{\text {загр }}$ и тепловой эффективности $\zeta$ на $40 \%$ ниже, хотя соотношения между режимами 1, 2 и 3 сохраняются.

3. Полученные зависимости коэффициентов $\varepsilon_{\text {загр }}, \mathrm{k}_{\text {загр }}$ и $\zeta$ рекомендуются при проектировании конвективных поверхностей нагрева УК, в том числе и систем наземного энергообеспечения авиационно-космической техники.

\section{Литература}

1. Тепловой расчет котельньх агрегатов (Нормативный метод). Изд. 3-е, переработанное и дополненное. - Издательство НПО ЦКТИ СПб, 1998. $-256 c$

2. Канило, П. М. Анализ энергоэкологических показателей тепловых электростаничй [Text] / П. М. Канило, М. В. Саранина // Проблемы машиностроения. - 2012. - T. 15, №3-4. - C. 100-106.

3. Корниенко, В. С. Интенсивность процессов загрязнения поверхностей нагрева утилизационных котлов при сжигании водомазутных эмульсий [Текст] / В.С. Корниенко // Авиационно-космическая техника и технология. - 2017. - №1. - С. 48-53.
4. Salih, S. Y. Water-diesel emulsion: areview [Text] / S. Y. Salih // International Journal of Advances in Engineering \& Technology. - 2017. - Vol. 10, № 3. - P. 429-436.

5. Минько, К. Б. Гидравлическое сопротивление и эффективная теплопроводность засыпок из сферических частии [Текст]/ K. Б Минько, В. И. Артемов, Г. Г. Яньков // Весник МЭИ. - 2011. - № 4. - C. 47-55.

6. Performance and Emissions of diesel engine fuelled with water-in-diesel emulsion [Text] / S. Watanabe, W. J. Yahya, A. M. Ithnin, H. Abd Kadir // Journal of the Society of Automotive Engineers Malaysia. - 2017. - Vol. 1, № 1. - P. 12-19.

\section{References}

1. Teplovoi raschet kotel'nykh agregatov (Normativnyi metod). Izd. 3-e, pererabotannoe $i$ dopolnennoe [Thermal calculation of boiler units (Normative method). Ed. 3rd, revised and enlarged]. St. Petersburg, NGO CKTI Publ., 1998. 256 p.

2. Kanilo, P. M., Saranina, M. V. Analiz energoekologicheskikh pokazatelei teplovykh elektrostantsii [Analysis of energy and ecological parameters of thermal power plants]. Problemy mashinostroeniya, 2012, vol. 15, no. 3-4, pp. 100-106.

3. Korniyenko, V. S. Intensivnost' protsessov zagriazneniia poverkhnostei nagreva utilizatsionnykh kotlov pri szhigani vodomazutnykh emul'sii [Intensivity of pollution processes in exhaust gas boilers at burning water-fuel emulsion]. Aviatsionno - kosmicheskaia tekhnika i tekhnologiia - Aerospace technic and technology, 2017, no. 1, pp. 48-53.

4. Salih, S. Y. Water-diesel emulsion: a review. International Journal of Advances in Engineering \& Technology, 2017, vol. 10, no. 3, pp. 429-436.

5. Min'ko, K. B, Artemov, V. I., Ian'kov, G. G. Gidravlicheskoe soprotivlenie i effektivnaia teploprovodnost' zasypok iz sfericheskikh chastits [Hydraulic resistance and effective thermal conductivity of backfill from spherical particles]. Vestnik MEI - Vestnik MEI, 2011, no. 4, pp. 47-55.

6. Watanabe, S. Yahya, W. J., Ithnin, A. M., Abd Kadir, H. Performance and Emissions of diesel engine fuelled with water-in-diesel emulsion. Journal of the Society of Automotive Engineers Malaysia, 2017, vol. 1, no. 1 , pp. $12-19$.

Поступила в редакцию 20.12.2017, рассмотрена на редколлегии 21.02.2018

\section{ВПЛИВ ЗАБРУДНЕННЯ НА ТЕПЛОВУ ЕФЕКТИВНІСТЬ ПОВЕРХОНЬ НАГРІВУ УТИЛІЗАЦІЙНИХ КОТЛІВ ПРИ ВИКОРИСТАННІ ВОДОПАЛИВНИХ ЕМУЛЬСІЙ НА ОСНОВІ МАЛОВ'ЯЗКИХ ПАЛИВ}

\section{В. С. Корнієнко, А. М. Радченко, А. А. Андрєєв, Ю. Г. Щербак}

При спалюванні водопаливних емульсій з водовмістом 30 \% завдяки зменшенню швидкості низькотемпературної корозії до допустимого рівня 0,25 мм/рік в утилізаційному котлі можлива установка конденсаційних поверхонь нагріву. Прийняті значення насипної густини забруднень при спалюванні малов'язких палив і водопаливних емульсій на їх основі. Отримано залежності товщини шару забруднень від температу- 
ри стінки на основі наявних експериментальних даних з інтенсивності забруднення при різних значеннях температури стінки і розрахункових значеннях насипної щільності шару забруднень. Змінний характер залежностей вказує на необхідність визначення значень товщини забруднень для кожного відповідного діапазону значень температури стінки. На основі отриманих залежностей середньої товщини забруднень від температури стінки, а також значень коефіцієнта еквівалентної теплопровідності побудовано залежності коефіцієнтів забруднення від температури стінки. Отримані залежності показують, що при однакових температуpax стінки і спалюванні водопаливних емульсій з водовмістом $30 \%$ значення коефіцієнтів забруднення істотно нижче, ніж при спалюванні необводнених. Порівняння значень коефіцієнта забруднення підтверджує достовірність проведених на експериментальній установці досліджень процесів забруднення і аналітично визначених величин. Проведено розрахункові дослідження і побудовано залежності коефіцієнтів теплопередачі забрудненої поверхні при температурах поверхні нагрівання в діапазоні $70-210{ }^{\circ} \mathrm{C}$ при спалюванні малов'язких палив і водопаливних емульсій на їх основі. Доцільно оцінювати вплив забруднень за значеннями теплової ефективності, оскільки вони дозволяють виявити вплив на величину коефіцієнта забруднення труб i нерівномірності їх омивання. Отримані залежності коефіцієнтів забруднення, теплопередачі і теплової ефективності рекомендуються при проектуванні конвективних поверхонь нагріву утилізаційних котлів.

Ключові слова: утилізаційний котел, поверхня нагріву, забруднення, водопаливна емульсія, малов'язке паливо.

\section{INFLUENCE OF POLLUTION ON THE HEAT EFFICIENCY OF HEATING SURFACES WITH USING WATER-FUEL EMULSION BASED ON LOW-VISCOSITY FUELS}

\section{S. Kornienko, A. N. Radchenko, A. A. Andreev, Y. G. Shcherbak}

When burning water-fuel emulsions with a water content of $30 \%$ due to decrease in the rate of low-temperature sulfuric acid corrosion to an acceptable level of $0.25 \mathrm{~mm} /$ year, condensation heating surface can be installed in the exhaust gas boilers. On the basis of studies and literature data, the values of the bulk density of pollutions in the burning of low-viscosity fuels and water-fuel emulsions based on them were adopted. Relations of the pollution layer thickness on the wall temperature on the basis of the available experimental data on the intensity of pollution at different values of the wall temperature, the literature data, and the calculated values of the bulk density of the pollution layer are obtained. The variable nature of the relations indicates the need to determine the values of the pollution thickness for each appropriate range of wall temperature values. Based on the obtained relations of the mean thickness of the pollutions on the wall temperature, as well as the values of the coefficient of equivalent thermal conductivity, the relations of the pollution coefficients on the wall temperature are constructed. The obtained relations show that at the same wall temperatures during the combustion of water-fuel emulsions with a water content of 30\% the value of the pollution coefficients is significantly lower than when burning the non-watered fuel. Comparison of the values of the pollution factor confirms the reliability of the studies of pollution processes and analytically determined values carried out in the experimental setup. The relations of the heat transfer coefficient of the polluted surface at the heating surface temperatures in the range of $70-210{ }^{\circ} \mathrm{C}$ for the combustion of lowviscosity fuels and water-fuel emulsions based on them were proposed. It is expediently to evaluate the effect of impurities on the values of thermal efficiency, because they allow to reveal the overall effect on the value of the pollution coefficient and the unevenness of their blowing. The obtained relations of the pollution coefficients, heat transfer and thermal efficiency in the design of convective heating surfaces for exhaust gas boilers are proposed.

Keywords: exhaust gas boiler, heating surface, pollution, water-fuel emulsion, low-viscosity fuel.

Корниенко Виктория Сергеевна - преподаватель, Херсонский филиал Национального университета кораблестроения имени адмирала Макарова, Херсон, Украина, e-mail: kornienkovika1987@gmail.com.

Радченко Андрей Николаевич - канд. техн. наук, доцент, докторант, Национальный университет кораблестроения имени адмирала Макарова, Николаев, Украина, e-mail: nirad50@gmail.com.

Андреев Артем Андреевич - канд. техн. наук, доцент, Херсонський филиал Национального университета кораблестроения имени адмирала Макарова, Херсон, Украина, e-mail: andreev.cme@gmail.com.

Щербак Юрий Георгиевич - канд. техн. наук, доц., Черноморский национальный университет им. П. Могилы, Украина.

Kornienko Victoriya Sergeevna - teacher, Kherson branch of Admiral Makarov National University of Shipbuilding, Kherson, Ukraine, e-mail: kornienkovika1987@gmail.com.

Radchenko Andrey Nikolaevich - PhD, Associate Professor, doctorant, Admiral Makarov National University of Shipbuilding, Nikolayev, Ukraine, e-mail: nirad50@gmail.com.

Andreev Artem Andreevich - PhD, Associate Professor, Kherson branch of Admiral Makarov National University of Shipbuilding, Kherson, Ukraine, e-mail: andreev.cme@gmail.com.

Shcherbak Yuri Georgievich - PhD, Assistant Professor, Petro Mohyla Black Sea National University, Mykolayiv, Ukraine. 